\title{
Proceedings of the AMCP Partnership Forum: NCPDP Electronic Prior Authorization Standards- Building a Managed Care Implementation Plan
}

\author{
AMCP Electronic Prior Authorization Work Group
}

\section{SUMMARY}

Today's manual prior authorization (PA) process is often viewed by providers, payers, pharmacists, and patients as cumbersome, costly, and inefficient. The recent approval by the National Council for Prescription Drug Programs of a standard transaction for electronic prior authorization (e-PA) has paved the way for more rapid and efficient processing of PA requests. On April 23, 2014, the Academy of Managed Care Pharmacy (AMCP) convened a meeting of key stakeholders to explore how to support the process of implementing the new standard transactions for e-PA and to recommend activities and programs that AMCP can promote to speed the adoption of e-PA. This Partnership Forum included individuals from managed care organizations, the pharmaceutical industry, pharmacy benefit managers, electronic prescription hubs or networks, and health information technology vendors.

The speakers and panelists recommended that AMCP should develop measurable goals for staged and full implementation of e-PA. To accomplish this, it was recommended that AMCP work to collaborate with organizations representing these stakeholders. Additionally, it was recommended that AMCP develop managed care e-PA implementation and e-PA criteria guides, as well as an e-PA scorecard.

J Manag Care Spec Pharm. 2015;21(7):545-50

Copyright $\odot 2015$, Academy of Managed Care Pharmacy. All rights reserved.

$\mathrm{O}$ n April 23, 2014, the Academy of Managed Care Pharmacy (AMCP) held a meeting of multiple stakeholders to explore how to best facilitate the implementation of the new National Council for Prescription Drug Programs (NCPDP) standard transactions for electronic prior authorization (e-PA). ${ }^{1}$ This Partnership Forum included individuals from managed care organizations (MCOs), the pharmaceutical industry, pharmacy benefit managers (PBMs), electronic prescription hubs or networks, and health information technology vendors.

The goal of the forum was to develop measurable goals for staged and full implementation of e-PA in MCOs and to consider priorities and methods to encourage adoption of e-PA by all stakeholders.

\section{Prior Authorization in Managed Care Pharmacy}

Speakers and panelists described pharmacy prior authorizations (PAs) as an important tool pertaining to several categories of managed care utilization management activities, including step therapy, practice guideline or pathway use, specialist prescribing restrictions, and authorization requirements related to benefit design (e.g., Medicare Part B benefit eligibility). They agreed that PA is an essential tool to ensure the appropriate use of medical and pharmaceutical technologies, to assist in improving patient care and safety, and to improve cost-effective patient outcomes. Further, they prognosticated that the use of PA requirements would likely rise with the increasing use of new and complex specialty pharmaceuticals and other technologies.

Despite the importance of PAs to managed care pharmacy, Speaker Anita Murko pointed to evidence showing that providers view today's manual (i.e., paper, telephone, and facsimile) and web-based PA processes as cumbersome and costly, often taking days to complete..$^{2-4}$ Murko cited studies estimating the annual cost from PA burden to be $\$ 11,440$ per pharmacist. ${ }^{5}$ She also cited a 2009 study in Health Affairs showing that, on average, physician offices spend 20 hour per week on all PA interactions with plans and insurers. ${ }^{6}$ Practices spent $\$ 23$ billion to $\$ 31$ billion on all payer administration interactions. ${ }^{6}$ Murko and other speakers pointed to a survey showing that streamlining medication PA was a top priority for $91 \%$ of providers and that $28 \%$ of physicians surveyed would switch their electronic medical record (EMR) vendor for one that offered e-PA capabilities. ${ }^{7,8}$

Speakers and panelists agreed that the current manual PA process also likely influences prescription abandonment rates and, ultimately, patient care. Further, there was recognition that community pharmacists are frustrated by the minimal communication from health plans or PBMs and by being the ones who are often responsible for informing patients that a prescription needs a PA.

\section{Testing the NCPDP e-PA Transaction Standard}

Speaker Allison Orenstein reviewed the CVS e-PA pilots that were the offshoot of a 2006 industry panel convened by the Centers for Medicare \& Medicaid Services and the Agency for Healthcare Research and Quality, which recommended that a new set of XML-based transactions be developed for medication PA, since the X12 278 was determined not to be adequate. ${ }^{9}$ 
In 2011-2012, industry participants piloted e-PA transactions based on the draft e-PA transaction standard. The standard was enhanced based on the pilot results and resulted in the July 2013 publication of e-PA SCRIPT Standard. The standard integrates e-PA into the regular EMR workflow, responding quickly to e-PA requests and asking physicians the minimal number of appropriate questions to allow them to use e-PA efficiently.

\section{How Was the Pilot Constructed?}

Speaker Orenstein detailed the specifics of the 2012 CVS e-PA pilot, which used the electronic prescription network Surescripts and 2 software vendors, Allscripts ePrescribe and NaviNet/CoverMyMeds. ${ }^{8}$ More than 3,000 physicians participated in the pilot, which ended in February 2013. The pilot program successfully tested e-PA capabilities across all lines of business, including employer, Medicare, and Medicaid, and across the spectrum of PA types: quantity limits, step therapy, drug exclusions/medical exceptions, and conventional PA criteria. The e-PA process used standard and custom PA criteria, and it supported MCOs with semi- and nonautomated processes. ${ }^{8}$

\section{What Were the Pilot Findings?}

The CVS pilot verified that the e-PA standard allowed prescribers to perform "end-to-end" PA requests in 1 e-prescribing session in 5 minutes or less. The pilot showed, however, that most prescribers sent the PA request into a work queue and completed the PA request in a separate e-prescribing session. The pilot also studied approval and rejection rates and found that there was only a $1 \%$ variance in the PA decision between manual and e-PA processes. ${ }^{8}$

An important lesson learned from this e-PA pilot was that incorporating "skip logic" and decision trees in the criteria interface was critical to achieving full automation of the system. It also was clear that human intervention (on the part of managed care) was sometimes necessary; therefore, a manual entry point and bypass of the process must be incorporated into the system. Some of the EMRs in the pilot were able to prepopulate patient information fields, although this was dependent on the sophistication of each physician's EMR software application.

The pilot also identified unintentional duplicate submissions for the same PA as a possible error source. In the pilot program, when physicians sent multiple submissions for the same PA, it was usually because they clicked "send" more than once.

According to Surescripts Speaker Melissa Brown, MCOs reviewing the pilot considered the findings encouraging; Brown's organization has since expanded the use of e-PA to a number of large organizations, including Humana and Prime Therapeutics.

\section{Forum Feedback on Pilot Results}

Forum panelists agreed that the queue approach, as opposed to "end-to-end" e-PA completion in 1 e-prescribing session, likely would lead to more members reaching the pharmacy without a PA. The consensus of the forum was that standardization of the e-PA interface and incorporation into comfortable workflow is key to the success of the e-PA transaction standard in the physician office. Similarly, panelists agreed that prepopulating of patient information fields by EMRs is important for efficient and rapid filing of a PA request. Panelists also voiced the opinion that they would have preferred to see an improvement in PA acceptance rates with the electronic process, since an electronic approach should diminish the frequent denials based on missing or incomplete information.

Importantly, the panel agreed with Speaker Jeff Taylor's observation that the pilot did not explore adequately the different processes and e-PA capabilities for PA requests traditionally adjudicated under the medical benefit (e.g., physician officeadministered specialty injectables). ${ }^{10}$ Panelists also identified the need for e-PA to address the complexity of the medical/ pharmacy drug benefit design, noting that some MCOs cover some drugs or drug categories under the medical benefit but manage their utilization under the pharmacy benefit. Another example of the complexity was plans that cover a drug under both the medical and pharmacy benefit.

The panel consensus was that future e-PA iterations should allow for the authorization to be linked to the claim system (i.e., medical or pharmacy) that will be paying the claim. Adding medical-benefit PAs to the NCPDP e-PA framework was ranked as a needed future e-PA enhancement by the panel. The panel noted that adding medical-benefit e-PA functionality would require additional data fields to be added to the NCPDP standard, such as date of service, place of service, Current Procedural Terminology (CPT) codes, and Healthcare Common Procedure Coding System codes. Additionally, some panelists noted that there is a strong likelihood that HIPAA requirements would need to be addressed for physician-office e-PA, since the HIPAA exclusion granted to pharmacy-related e-prescribing transactions likely will not apply.

The panelists also seconded Taylor's observations that well-designed and tested PA criteria were critical to the success of e-PA. Panelists agreed that criteria sets can and will differ by MCO or benefit, but that all criteria should be designed and tested for efficiency and use standardized coding structures such as International Classification of Diseases, Ninth Revsision, Clinical Modification (ICD-9-CM), CPT, and Logical Observation Identifiers Names and Codes (LOINC). Embedding standardized coding in criteria sets would enable EMRs to prepopulate fields, reducing practice time needed to complete the PA request and helping to eliminate errors related to missing information. Criteria sets also should optimize the number of binary or multiple-choice questions that need to be answered. Additionally, there was agreement that complete 
elimination of open-ended questions is not practical, but it was recommended to work towards minimizing their number. Panelists also agreed that e-PA will be most attractive to prescribers when manual input of criteria responses is minimized; most criteria responses should be able to be answered in an automated fashion by the EMR.

The consensus of the forum was that the pilot did not clearly address questions about e-PA's return on investment (ROI). While the CVS pilot identified efficiencies for physician offices (e.g., reduced time and incorrect filing of PA requests), they were not explored fully for community pharmacy, managed care, and patients. One panelist revealed that implementing an e-PA pilot eliminated PAs filed and rejected because of missing required information. ${ }^{11}$ The AMCP e-PA panelists agreed that the ROI message will be important to all stakeholders and will help persuade those who are wavering on adoption. The panel identified shorter turnaround times for PA requests as a surrogate ROI indicator for improved patient outcome. One panelist stated that their e-PA turnaround time was reduced by $90 \%$ compared with conventional PA use. Other panelists identified the tangential efficiency that e-PA brings when authorizations need to be renewed.

Speaker Tony Schueth noted that the e-PA standard would drive more accurate formulary and benefit files, which would drive faster and more accurate patient benefit match rates. The panel urged AMCP to engage with other professional pharmacy and medical societies to develop and disseminate the ROI message.

\section{The e-PA Interface}

Speaker Schueth observed that while physicians generally have been slow to incorporate EMRs into their practices, it seems that the possibility of e-PA could motivate action. He noted that physician surveys list e-PA functionality as a top EMR priority. He also noted that EMR vendor consolidations (i.e., that the top 5 vendors represent approximately $52 \%$ of the total market) bodes well for e-PA implementation. Schueth also saw the delay of 2 critical projects-the move to ICD-10 (from ICD-9) coding and the next stage of meaningful use standards-as perhaps being favorable for e-PA adoption. He suggested that a window of opportunity may now exist for EMR vendors who wish to move forward and employ the NCPDP e-PA standard transactions. His communications with the EMR market leaders showed their readiness to implement in the first quarter of $2015 .^{12}$

Schueth listed inaccurate and incomplete MCO formulary and benefit $(F \& B)$ files as the greatest contributors to e-prescribing difficulties. F\&B files should supply, at the drug-benefit level, an accurate list of formulary choices or alternatives, plan limits and exclusions (e.g., PA, step therapy, and quantity limits), and formulary tiering to the EMR platform. The forum participants underscored Schueth's observation that the accuracy of F\&B information is critical to the success of e-PA implementation and that MCOs should test these files frequently. ${ }^{12}$

\section{Intermediary Network Exchange and e-PA}

Surescripts Speaker Brown discussed the network e-prescribing intermediaries that provide the common secure link between all participants needing to exchange information: prescriber, PBM, EMR vendor, and pharmacy. ${ }^{7}$ To ease the EMR programming burden, including the development of graphic user interface components, some intermediaries are providing optional application programming interfaces (APIs) and publishing client software codes that can be used by the EMR vendors to build their integration. The network APIs typically include EMR specifications for routines, data structures, object classes, variables, and remote calls. Forum participants noted that using an intermediary is not required for e-PA and that some PBMs may choose to interface directly with an EMR vendor, especially if the EMR vendor accounts for a substantial portion of their physician connectivity.

\section{State Legislative Efforts}

From an EMR vendor perspective, Speaker Schueth noted that state-specific PA legislation could slow or complicate adoption of the e-PA standard. He pointed to state legislation defining PA requirements as confusing EMR vendors. "Some EMRs don't know where to start. We really haven't defined what standard will be used, as each state seems to be coming up with its own." Several states are in various stages of implementing uniform PA standards or considering the viability of e-PA mandates. ${ }^{13,14} \mathrm{~A}$ number of organizations (including AMCP) are educating state legislators about the e-PA standards. ${ }^{15,16}$ Panelists underscored the importance of AMCP continuing with these efforts.

\section{When Prospective Physician Office e-PA Breaks Down}

When MCOs implement e-PA fully, there should be few instances in which the physician does not learn that a drug requires PA until the prescription reaches the pharmacy. If these instances occur, the NCPDP SCRIPT Standard provides an electronic communication option, called an RxChange Request, which can be initiated by the pharmacy. This RxChange Request can be used to not only alert the physician that PA is required but also to request permission to carry out therapeutic substitutions based on formulary criteria or to review the drug requested. The RxChange Request also can enable MCO benefits coordination and include contact phone numbers to the physician's office to initiate the PA. The physician's response to the alert is called an RxChange Response transaction, and this may include information about the approved PA. ${ }^{17}$ EMR 
vendors are working on many issues related to the e-PA process, including how the workflow would handle retrospective versus prospective e-PA requests and which hub to use.

\section{Forum Recommendations}

The NCPDP standard transactions have been established and pilot tested, but this does not guarantee adoption and implementation of e-PA. Awareness of the standard transactions is lacking, and information systems, at the level of the payer, PBM, EMR vendor, and physician offices, will have to adapt to utilize this new capability.

\section{Phased Implementation Approach Recommendation}

Although physicians, payers, and patients will expect as much automation as possible, the forum concluded that a fully automated e-PA system may need to evolve through at least 2 stages during 2015-2017. A required component of Phase 1 would be to transmit timely and accurate $F \& B$ and eligibility data to help reduce errors in PA requests. Additionally, Phase 1 would require EMR vendors to apply the F\&B data to the e-prescribing transaction. While an optimal Phase 1 would have EMRs being interrogated to supply responses to e-PA criteria (e.g., ICD-9 or 10 codes), the panel observed that Phase 1 will likely require physicians to continue to manually supply the needed criteria responses. Phase 2 would add a system to e-PA that would automatically interrogate the medical record to populate the responses to the PA criteria instead of requiring manual input by the physician. Adding this functionality would allow for automated processing and response by the EMR.

To launch e-PA Phase 1, the forum recommended that managed care pharmacy should broadly and rapidly commit to the pharmacy e-PA component of the NCPDP SCRIPT standard. The panel suggested that broad stakeholder education and successful e-PA implementation would help to minimize unnecessary state mandates and proposals. Additionally, there should be a commitment to sending PA and other benefit flags to the group level by the payer using the F\&B standard. They further recommended that MCOs and physician practices consider adding e-PA performance guarantees to their PBM and e-prescribing contracts to speed adoption.

The forum also recommended that the term "pilot program" not be used by MCOs and PBMs during the Phase 1 implementation, since it connotes a program that is not ready for broad implementation. Sufficient pilots have been conducted and PBMs and EMRs are able to implement.

\section{A 3-Pronged Educational Approach}

The panel recommended a 3-pronged approach to e-PA education and implementation. This approach includes the development of (1) an MCO e-PA implementation guide, (2) an e-PA scorecard, and (3) an e-PA criteria development guide.
1. Develop an e-PA Implementation or "Best Practices" Guide. The panel recommended that AMCP spearhead the development of an e-PA implementation guide. The guide would include a list of structural components instrumental to a successful e-PA rollout in an MCO. The resource should include a task list to aid MCOs, PBMs, transaction hubs, e-PA vendors, and EMR vendors in developing their e-PA testing and implementation plans. The panel recommended that the guide be continuously updated based on key learnings with successive MCO e-PA rollouts.

Among the more important components of the guide would be creating materials for facilitating a strong educational effort directed toward physician practices and including concise ROI messages. The panel noted that building a critical mass of payers using e-PA, starting in early 2015, is needed to show physicians that it is time to engage in e-PA. Without this critical mass of payers, physicians and their EMR vendors are less likely to embrace e-PA.

2. Develop an e-PA Scorecard. The panel also recommended that an e-PA scorecard, tracking key performance indicators, would promote early e-PA adoption and provide a benchmark for moving forward to an e-PA process with fully integrated EMR functionality. This scorecard also could highlight the savings that MCOs, physicians, and patients would receive from a successful e-PA rollout. Additionally, the scorecard could serve as a communication tool to educate state legislators about unnecessary PA mandates.

According to the panel, the scorecard approach could also build support for e-PA certification and quality reporting. Creating a Healthcare Effectiveness Data and Information Set and/or Medicare Star rating measures or accreditation standards based on "percentage of all PAs transacted electronically from the EMR," for example, might serve to drive e-PA adoption.

3. Develop a Criteria Development Guide. The panel recommended that AMCP work with stakeholders to create a "criteria reference book" with numerous examples of PA criteria updates. The reference should address efficient design and testing and demonstrate the use of standardized coding structures (e.g., ICD-9-CM, CPT, and LOINC codes). The criteria guide should be designed to facilitate full integration of e-PA with the EMR. 


\section{Authors}

\begin{abstract}
AMCP ELECTRONIC PRIOR AUTHORIZATION WORK GROUP PARTICIPANTS: ELIAS AYELE, Research \& Development, Epic; MORGAN BOJORQUEZ, Manager, Pharmacy Clinical Integration, Humana; MELISSA BROWN, Director of Benefits, Point of Care Messaging, Product Management, Surescripts; DAVID FIDLER, Director, ePrescribing and Clinical Interoperability, ESI; JACQUES FU, Chief Technology Officer, AssistRx; PEGGY GREENBERG, President, Peggy Greenberg Consulting and Training (moderator); MAYLISA HAZELWOOD, Clinical Pharmacist, Pharmacy Operations, Blue Cross Blue Shield of Massachusetts; MANOJ KUMAR, Senior Director, Clinical Products, Catamaran; CHRISTOPHER LEGGETT, Director, Health IT and Care Delivery, U.S. Public Policy, GlaxoSmithKline; JEFF LINDOO, Vice President, Governmental \& Regulatory Affairs, Thrifty White Pharmacy; ANITA C. MURCKO, Assistant Clinical Professor, Arizona State University, Department of Biomedical Informatics; ALLISON ORENSTEIN, Director, Physician Connectivity \& Engagement, CVS Caremark; MIKE PENN, Director of Policy, Pfizer; ROGER PINSONNEAULT, Vice President, Business Development, RelayHealth; EDWARD (ED) PLUT, Director, Product Management, Payer \& Life Sciences, Allscripts; JOE REINARDY, Principal, CenterX; CAMERON SAWICKI, Planning Lead, Genentech; DAVID SCAGLIONE, Director of Physician Connectivity, Prime Therapeutics; MATT SCANTLAND, Co-founder and Principal, CoverMyMeds; SHARI SCHNEIDER, Manager, Third Party Operations, Walgreens; TONY SCHUETH, CEO \& Managing Partner, Point-of-Care Partners; SRI SWARNA, CEO, Agadia Systems; JEFF TAYLOR, Pharmacy Director, Aetna; and LAURA TOPOR, President, Granada Health.
\end{abstract}

\section{AMCP STAFF: KEVIN BRUNS, Senior Director of} Communications; MARY JO CARDEN, Director of Regulatory Affairs; BERNADETTE EICHELBERGER, Director of Pharmacy Affairs; SUSAN OH, Assistant Director of Pharmacy Affairs; EDITH ROSATO, Chief Executive Officer; TODD SEGA, Senior Manager of Pharmacy Affairs; PUNEET SINGH, Executive Resident in Association Management; and RUBY SINGH, Director of Education.

AUTHOR CORRESPONDENCE: Bernadette Eichelberger, Director of Pharmacy Affairs, Academy of Managed Care Pharmacy, 100 N. Pitt St., Ste. 400, Alexandria, VA 22314.

E-mail: beichelberger@amcp.org.

\section{DISCLOSURES}

AMCP staff declare no conflicts of interest or financial interests in any product or service mentioned in this article, including grants, employment, gifts, stock holdings, or honoraria.

The AMCP Partnership Forum: NCPDP Electronic Prior Authorization Standards-Building a Managed Care Implementation Plan and the development of this report were supported by Agadia Systems, Inc.; Amgen; AssistRx; CoverMyMeds, LLC; Genentech, Inc.; GlaxoSmithKline PLC; Merck; Pfizer, Inc.; and Thrifty White.

\section{ACKNOWLEDGMENTS}

The AMCP Electronic Prior Authorization Work Group would like to express its appreciation to Stanton R. Mehr of SM Health Communications for his assistance in reporting on the deliberations of this AMCP Partnership Forum and in producing this manuscript.

\section{REFERENCES}

1. National Council of Prescription Drug Programs. SCRIPT electronic prior authorization transactions overview. August 2013. Available at: http://www. ncpdp.org/NCPDP/media/pdf/NCPDP_SCRIPT_ePA_Standard.pdf. Accessed May 16, 2015

2. Medical Society of the District of Columbia. Prior authorization: impact on patient care in the District of Columbia. A survey of the members of the Medical Society of the District of Columbia. May 7, 2012. Available at: http:// library.constantcontact.com/download/get/file/1102805358610-210/MSDC+ Survey+Executive+Summary+Final.pdfundefined. Accessed May 16, 2015.

3. Morley CP, Badolato DJ, Hickner J, Eppling JW. The impact of prior authorization requirements on primary care physicians'offices: report of two parallel network studies. J Am Board Fam Med. 2013;26(1):93-95. Available at: http://www.jabfm.org/content/26/1/93.long. Accessed May 29, 2015.

4. Morra D, Nicholson S, Levinson W, Gans DN, Hammons T, Cassalino LP. U.S. physician practices versus Canadians: spending nearly four times as much money interacting with payers. Health Aff (Millwood). 2011;30(8): 1443-50. Available at: http://content.healthaffairs.org/content/30/8/1443. long. Accessed May 29, 2015.

5. Lennertz $\mathrm{M}$, Wertheimer A. Is prior authorization for prescribed drugs cost-effective? Drug Benefit Trends. 2008;20(4):136-39.

6. Casalino LP, Nicholas S, Gans DN, et al. What does it cost physician practices to interact with health plans? Health Aff (Millwood). 2009;28(4):w533-43.

7. Murcko AC. e-PA perspective 1: physician and patient experience. Presented at: AMCP Partnership Forum: NCPDP Electronic Prior Authorization Standards-Building a Managed Care Implementation Plan; April 23, 2014; Arlington, VA.

8. Brown M. NCPDP Electronic prior authorization standards: building a managed care implementation plan. Presented at: AMCP Partnership Forum: NCPDP Electronic Prior Authorization Standards-Building a Managed Care Implementation Plan; April 23, 2014; Arlington, VA.

9. Orenstein A. Lessons learned from the CVS Caremark pilot. Presented at: AMCP Partnership Forum: NCPDP Electronic Prior Authorization Standards_-Building a Managed Care Implementation Plan; April 23, 2014; Arlington, VA.

10. Taylor J. e-PA perspective 2: expectations of managed care pharmacy. Presented at: AMCP Partnership Forum: NCPDP Electronic Prior Authorization Standards-Building a Managed Care Implementation Plan; April 23, 2014; Arlington, VA.

11. Academy of Managed Care Pharmacy. How managed care can ready their PA criteria to support the rapid implementation of electronic PA as part of E-prescribing (webinar). May 21, 2014. Available at: http://www.amcp. org/webinars/.

12. Schueth T. E-prescribing vendor approach to NCPDP standard and meeting managed care needs. Presented at: AMCP Partnership Forum: NCPDP Electronic Prior Authorization Standards—Building a Managed Care Implementation Plan; April 23, 2014; Arlington, VA.

13. State of New Mexico. Senate Bill 296. LegiScan. First session, 2013. Available at: http://www.nmlegis.gov/Sessions/13\%20Regular/bills/senate/ SB0296.pdf. Accessed May 16, 2015.

14. Maryland Health Care Commission. Recommendations for implementing electronic prior authorizations: a report prepared for the Maryland General Assembly Joint Committee on Health Care Delivery and Financing. December 2011. Available at: http://mhcc.dhmh.maryland.gov/hit/ Documents/prior_auth_final.pdf. May 16, 2015. 
15. Fuller L, Guckian SK, Schwartz L, et al. Letter to state legislators serving on Health, Human Services, Insurance and/or Telecommunications and Information Committees nationwide. New uniform electronic prior authorization standard supplants the need for legislation. December 19, 2013. Academy of Managed Care Pharmacy. Available at: http://www.amcp.org/ WorkArea/DownloadAsset.aspx?id=17459.
16. Green LA. Letter to Kathleen Sebelius, Secretary, Department of Health and Human Services. Findings from the February 2014 NCVHS hearing on prior authorization for the pharmacy benefit; health plan identifier (HPID); electronic fund transfer (EFT)/electronic remittance advice (ERA); and, remaining operating rules. May 15, 2014. National Committee on Vital and Health Statistics. Available at: http://ncvhs.us/wp-content/ uploads/2014/05/140515lt2.pdf. Accessed May 16, 2015.

17. National Council of Prescription Drug Programs. SCRIPT standard implementation guide. Version 2013071. July 2013. Scottsdale, Arizona. 